\title{
Closer to Nature: The Role of MSCs in Recreating the Microenvironment of the Hematopoietic Stem Cell Niche in vitro
}

\author{
Patrick Wuchter Anke Diehlmann Harald Klüter \\ Institute of Transfusion Medicine and Immunology, Medical Faculty Mannheim, Heidelberg University, \\ German Red Cross Blood Service Baden-Württemberg-Hessen, Mannheim, Germany
}

\section{Keywords}

Hematopoietic stem cells $\cdot$ Hypoxia $\cdot$ Mesenchymal stromal cells · Microbioreactor · Microenvironment $\cdot$ Stem cell niche

\begin{abstract}
Background: The stem cell niche in human bone marrow provides scaffolds, cellular frameworks and essential soluble cues to support the stemness of hematopoietic stem and progenitor cells (HSPCs). To decipher this complex structure and the corresponding cellular interactions, a number of in vitro model systems have been developed. The cellular microenvironment is of key importance, and mesenchymal stromal cells (MSCs) represent one of the major cellular determinants of the niche. Regulation of the self-renewal and differentiation of HSPCs requires not only direct cellular contact and adhesion molecules, but also various cytokines and chemokines. The C-X-C chemokine receptor type 4/stromal cell-derived factor 1 axis plays a pivotal role in stem cell mobilization and homing. As we have learned in recent years, to realistically simulate the physiological in vivo situation, advanced model systems should be based on niche cells arranged in a three-dimensional (3D) structure. By providing a dynamic rather than static setup, microbioreactor systems offer a number of advantages. In addition, the role of low oxygen tension in the niche microenvironment and its impact on hematopoietic stem cells need to be taken into account and are discussed in this review. Summary: This review focuses on the role of MSCs as a part of the bone marrow niche, the interplay between MSCs and HSPCs and the most important regulatory factors that need to be consid-
\end{abstract}

karger@karger.com www.karger.com/tmh

Karger $\%$

BOPEN ACCESS
(C) 2022 The Author(s)

Published by S. Karger AG, Basel

This is an Open Access article licensed under the Creative Common Attribution-NonCommercial-4.0 International License (CC BY-NC) (http://www.karger.com/Services/OpenAccessLicense), applicable to the online version of the article only. Usage and distribution for commercial purposes requires written permission. ered when engineering artificial hematopoietic stem cell niche systems. Conclusion: Advanced 3D model systems using MSCs as niche cells and applying microbioreactor-based technology are capable of simulating the natural properties of the bone marrow niche more closely than ever before.

(c) 2022 The Author(s).

Published by S. Karger AG, Basel

\section{Introduction}

The stem cell niche in human bone marrow provides essential factors that regulate the proliferation and differentiation of human hematopoietic stem and progenitor cells (HSPCs). Direct cellular contact mediated by adhesion molecules, scaffolds, extracellular matrix, paracrine factors, spatial distribution, mechanical and shear forces and oxygen tension plays a role in governing stem cell fate [1-6]. As a result, modeling the highly dynamic framework of the hematopoietic stem cell niche in a three-dimensional (3D) environment is warranted. In recent years, microbioreactor-based systems have been able to mimic a number of crucial factors [7-10], but finding an optimal set of read-out assays to measure the effects on stem cells and their functional properties is challenging.

In this review, we analyze the most important regulatory factors and consider some of the most promising examples of 3D coculture and microbioreactor systems. Mesenchymal stromal cells (MSCs) represent an important part of the bone marrow niche and support normal hematopoiesis. However, there is mounting evidence 
that the niche microenvironment can also contribute to the pathogenesis of myeloid malignancies. Finally, the role of oxygen tension in the bone marrow niche is discussed.

\section{Regulatory Factors in the Stem Cell Niche and Their Effects on Stem Cell Engineering}

A number of regulatory factors in the stem cell niche have been identified in recent years, and their relevance for stem cell engineering has been addressed in various studies. Some of these important factors could be more precisely controlled in microfluid-based cell culture arrays or microbioreactors [9]. Table 1 gives an overview of the most important publications on the key issues (but is by no means exhaustive).

\section{Scaffold and Cellular Determinants of the Niche}

The scaffold has a substantial impact on the niche as well as on stem cells. It constitutes the macro- and microstructure of the niche and may also facilitate paracrine and autocrine activities of the matrix. For instance, higher cell proliferation rates could be observed under higher mechanical stresses. Additionally, control of cell shape via substrate size directs human MSC differentiation [1113]. MSCs represent one of the cellular determinants of the human stem cell niche in the bone marrow, along with numerous other cells, such as sympathetic neurons, macrophages, osteoblasts and endothelial cells, which all significantly influence the self-renewal and differentiation behavior of HSPCs [14-18]. However, it must be taken into account that the origins of MCSs - bone marrow, adipose tissue, cord blood - have a profound impact on the resulting cell population [19-24]. Similarly, the type of culture and expansion medium has an impact on the resulting cell population. The application of different MSC isolation and culture protocols has significantly hampered the comparability of experimental and clinical data from different laboratories and has posed a major obstacle for multicenter clinical trials [25, 26]. Manufacturing of cell products for clinical application in the European Community must be conducted in compliance with Good Manufacturing Practice (GMP). For GMPcompliant MSC expansion for clinical utilization, the use of xeno-free culture medium is warranted [27]. The strategy for quality control testing depends on the product's cell composition, the manufacturing process and the indication and target patient population. Important quality criteria in this sense are, among others, the immunophenotype of the cells, composition of the culture medium and the risk for malignant transformation, as well as aging and the immunosuppressive potential of the manufactured MSCs [28].

While the niche microenvironment supports not only normal hematopoiesis, it can also contribute to the patho- genesis of myeloid malignancies such as myelodysplastic syndromes (MDS) and acute myeloid leukemia (AML) [29], which led to the establishment of an experimental concept of "niche-induced" oncogenesis [30, 31]. MSCs from AML patients exhibited significant growth deficiency and impaired osteogenic differentiation capacity, which was molecularly reflected by a specific methylation signature affecting pathways involved in cell differentiation, proliferation and skeletal development [32]. Geyh et al. [33] demonstrated that MSCs from patients with several MDS subtypes showed reduced growth and proliferation behavior accompanied by premature replicative senescence. This was associated with specific methylation patterns that clearly separated MDS-MSCs from healthy controls. Furthermore, in MDS-MSCs, altered expression of key molecules involved in the interaction with bone marrow-derived (BM) HSPCs was demonstrated, particularly osteopontin, Jagged1, kit-ligand and angiopoietin, as well as several chemokines. Functionally, this translated into a significantly diminished ability to support BM HSPCs in long-term culture-initiating cell assays associated with reduced cell cycle activity [33].

Medyouf et al. [34] showed in a xenograft model that patient-derived MSCs (MDS MSCs) displayed a disturbed differentiation program and were essential for the propagation of MDS-initiating $\mathrm{Lin}^{-} \mathrm{CD} 34^{+} \mathrm{CD} 38^{-}$stem cells in orthotopic xenografts. Overproduction of niche factors such as N-cadherin, IGFBP2, VEGFA and LIF was associated with the ability of MDS MSCs to enhance MDS expansion. On the other hand, healthy MSCs adopted MDS MSC-like molecular features when exposed to hematopoietic MDS cells, indicative of instructive remodeling of the microenvironment. There is functional and molecular evidence for the view that MDS involves both the hematopoietic and stromal compartments and that a specific pattern of MSC hematopoietic cell interaction exists within the diseased BM that most likely contributes to the progressive BM clonality and fibrosis frequently observed in MDS patients [34]. This is in line with the findings of Chen et al. [35], who conducted massive parallel transcriptome sequencing of prospectively isolated mesenchymal elements from human low-risk MDS, revealing a common molecular signature, distinct from both normal and ex vivo expanded cells, characterized by cellular stress and upregulation of genes encoding inflammation-associated secreted factors with established inhibitory effects on hematopoiesis [35].

Figure 1 shows a summary of artificial hematopoietic niche approaches based on coculture with MSCs. However, to recreate a physiological niche microenvironment, it is necessary not only to obtain adequate niche cells (e.g., MSCs), but also to monitor the influence of the physical properties of the artificial compartment on the niche cells themselves. MSCs are responsive to not only biochemical, 
Table 1. Overview of key technical features for niche formation and interaction $[7,8,15,16,18,50,64,68,70-74,78,99-114,116-120]$

Author, year Technical features Species

Scaffold and advanced $2 D$ and $3 D$ culture techniques

Zhao et al. [7], 2007

Effects of shear stress on 3D human mesenchymal stem cell construct development in a Human

perfusion bioreactor system

Mendez-Ferrer et al. [16], 2010

Kim and Ma [70], 2012

Cimetta et al. [8], 2013

Ding and Morrison [101], 2013

Zhang et al. [102], 2013

Cell depletion experiments and spheroid formation, LTC-IC assay

Perfusion bioreactor flow experiments using 3D scaffolds

Microfluidic bioreactor for dynamic regulation in human pluripotent stem cells

Mouse stem cells on methylcellulose culture structures

Coculture techniques and transplants using hMSC and hCML in NSG mice

Choi et al. [103], 2015

hHSC on scaffold-based 3D biomaterial; 2D biomaterial platforms for stem cell niche engineering

3D culture of human CB-HSPCs in a degradable zwitterionic hydrogel

$3 \mathrm{D}$ collagen scaffold; cell proliferation assay; gene expression analysis

Mouse

Human

Human

Mouse

Human

Mouse

Bai et al. [73], 2019

Kafi et al. [104], 2019

Wilkinson et al. [72], 2019

Defined, albumin-free culture system that supports the long-term ex vivo expansion of

Human

functional mouse HSCs

Hafner et al. [105], 2020

Micromechanics ECM using HUVEC and MSC on porous scaffolds

Human

Human

Mouse

Coculture of HSPCS and niche cells

Walenda et al. [71], 2010

HSPC/MSC coculture, RT-PCR, immunophenotypic and immunoblot analysis

Human

Ehninger and Trumpp [106], 2011

Walenda et al. [107], 2011

Nestin+ MSC and G-CSF stimulation in HSC niche

Coculture hHSPC/MSC; CFU and murine transplant model

Human

Human

Human

Flow cytometry analysis of HPC, confocal laser scanning on stained MSC

Mouse

Ludwig et al. [68], 2014

Wuchter et al. [74], 2016

Ramalingam et al. [108], 2017

HSPC/MSC coculture, RT-PCR and Western blot, colony-forming cell assay

Coculture human BM-EC and human HSPC and hEC, fluorescent cell labeling and imaging

Human

Human

Human

Chip manufacturing and bioreactor setup, coculture of hHSPC/MSC

Mouse

Human

Gottwald et al. [100], 2019

Transgenic analysis and antibody staining on bone tissue sections

Mouse

Calvi et al. [15], 2003

Sieburg et al. [109], 2006

Anthony and Link [110], 2014

Zhou et al. [111], 2014

Busch et al. [112], 2015

Kusumbe et al. [113], 2016

Asada et al. [114], 2017

Pinho et al. [115], 2018

Cell clone dilution techniques and kinetics

Gene regulation and cytokine expression to establish a murine model of HSC niche

Mouse

Mouse

Immunofluorescent cell/DNA staining and expression analysis

Knock-in mice/flow cytometry/PCR genotyping/single-cell transplantation

Mouse

MSC differentiation assay and ELISA, BM transplantation experiments

RNA-Seq-analysis and competitive cell transplantation

Mouse

Mouse

Immunocell-labeling and FACS, cell depletion and transgenic mouse models

Mouse

Hypoxia

Rehn et al. [116], 2011

FACS analysis on hypoxic niche

Mouse

Nombela-Arrieta et al. [117], 2013 Hypoxic status induction and multiphoton microscopy, LSC analysis

Cheloni et al. [99], $2017 \quad$ CML cell lines cultured at hypoxic conditions; kinetics of BCR/Abl suppression

Kwon et al. [78], 2017

Hypoxia enhances cell properties of hMSCs

Mouse

Human

Human

Functional studies

Schaniel et al. [118], 2011

Lee-Thedieck et al. [119], 2012

Wuchter et al. [64], 2014

Hematopoietic progenitor cell assay, cell cycle analysis

Mouse

Hydrogel matrix elasticity analysis and atomic force microscopy

HPC transwell migration assay, BM-MSC immunofluorescent staining and ELISA

RNA sequencing and functional studies

Human

Velten et al. [120], 2017

Cell adhesion experiments and live-cell imaging

Human

Human

Mouse

Human

but also physical cues, such as substrate topography and stiffness [36, 37]. Frank et al. [38] aimed to simulate the dynamic structures of extracellular environments of the marrow in vivo and designed a "dynamic in vitro niche." They used a surrogate substrate for marrow-derived MSCs based on physically cross-linked hydrogels whose elasticity could be adapted dynamically by chemical stim- uli. Under frequent mechanical stress, MSCs grown on hydrogel substrates maintained the expression of STRO1 (a protein marker of MSCs) over 20 days, irrespective of substrate elasticity. Upon exposure to the corresponding induction media, these cultured MSCs could undergo adipogenesis and osteogenesis without requiring cell transfer onto other substrates. The surrogate substrate 


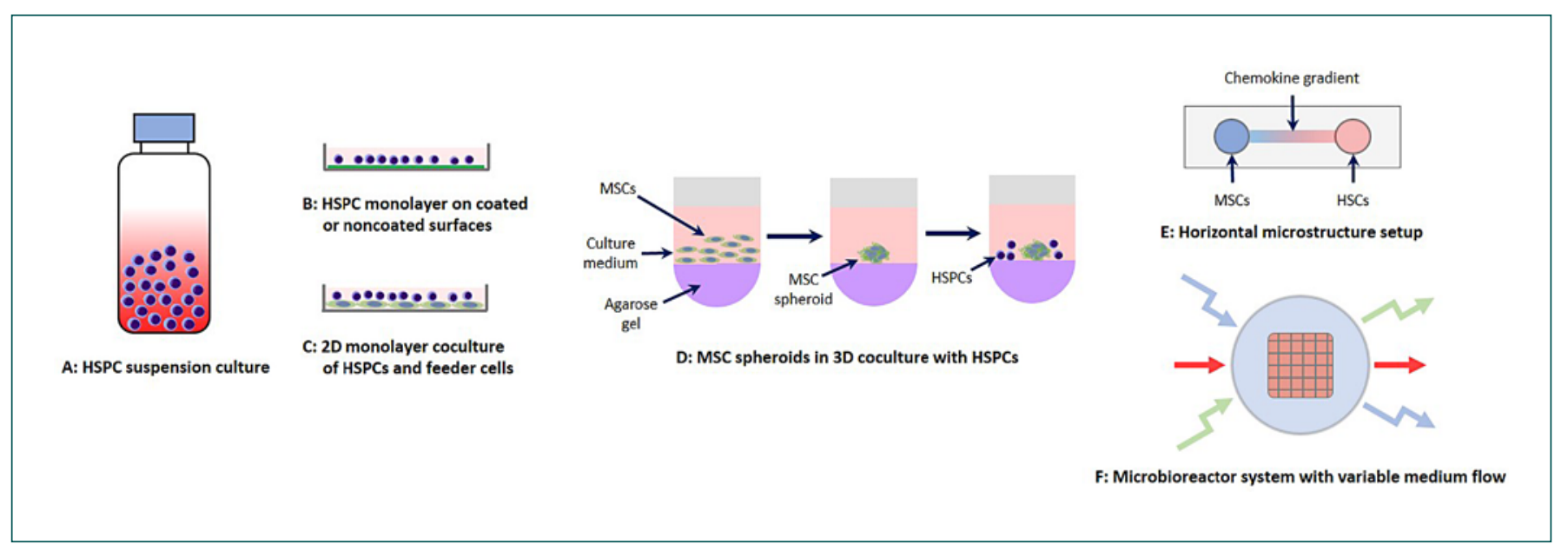

Fig. 1. Scheme for stepwise development of artificial HSPC niche systems. Step A: suspension culture is the simplest form of HSPC culture; however, even with added cytokines, it is not capable of maintaining stemness adequately for more than a few days (compare Walenda et al. [71]). B: HSPCs can be grown as monolayers on coated and noncoated surfaces, such as supporting membranes (compare Monzel et al. [50]). C: 2D coculture systems using a monolayer of feeder cells (e.g., MSCs) result in better HSPC survival and maintenance of stemness compared to suspension cul-

suppressed the proliferation of MSCs by up to $90 \%$ without any loss of multiple lineage potential when changing the substrate elasticity every 2 nd day. Such an approach can be used to obtain a better understanding of the effect of dynamic mechanical stresses on the fate and functionality of MSCs.

\section{Extracellular Matrix}

The complex microenvironment of the bone marrow comprises many different cell types (e.g., macrophages, adipocytes, fibroblasts), which together secrete a specialized extracellular matrix (ECM) [39]. ECM molecules represent an essential part of the stem cell niche and can actively modulate cell functions. Muth et al. [40] demonstrated that human umbilical cord blood (UCB) HSPC adhesion depends on the type of ligand, i.e., the type of ECM molecule, and the lateral, nanometer-scaled distance between the ligands (and the ligand type influences the dependency on the latter). For small fibronectin-derived peptide ligands, the critical adhesive interligand distance for UCBHSPCs was below $45 \mathrm{~nm}$. Fibronectin-derived and osteopontin-derived protein domains also supported cell adhesion at greater distances. In addition, the expression of the ECM protein thrombospondin-2 in UCB-HSPCs depends on the presence of the ligand and its nanostructured presentation. Functionally, thrombospondin-2 was proven to mediate the adhesion of UCB-HSPCs. In conclusion, UCB-HSPCs are sensitive to the nanostructure of their microenvironment, and they are able to actively modulate their environment by secreting ECM factors. ture of HSPCs (compare Ludwig et al. [68]). D: MSC spheroids generated on agarose gel in 3D coculture with HSPCs. E: horizontal microstructure setup for the analysis of chemotactic HSPC migration toward MSCs. MSCs are pre-incubated in one of the reservoirs, and HSPCs are added to the other reservoir after medium exchange (compare Wuchter et al. [64]). F: The use of microbioreactor systems allows further control of medium flow, shear force and oxygen tension (compare Gottwald et al. [100], Kim et al. [70] and Wuchter et al. [74]).

Kräter et al. [41] used BM-mimetic decellularized ECM scaffolds derived from MSCs to study the interaction between ECM and granulocyte colony-stimulating factormobilized peripheral blood HSPCs. Seeding freshly isolated mobilized peripheral blood HSPCs, adherent and nonadherent cells were found. Enhanced expansion and active migration of adherent cells mediated by ECM-incorporated stromal-derived factor could be detected. Probing cell mechanics, adherent cells displayed naïve cell deformation compared to nonadherent cells, indicating physical recognition of ECM material properties by focal adhesion. Integrin $\alpha \mathrm{IIb}(\mathrm{CD} 41), \alpha \mathrm{V}(\mathrm{CD} 51)$ and $\beta 3$ (CD61) were found to be induced. Integrin $\beta 3$ induction was identified to facilitate cell adhesion and migration and mediate ECM physical cues to modulate mobilized peripheral blood HSPC function. Scaffold physical parameters might be transduced through outside-in signaling via integrin $\alpha \mathrm{V} \beta 3$ and lead to mechanical and functional adaptation, resulting in increased stromal cell-derived factor 1 (SDF-1) recognition and chemotactic migration [41].

\section{Adhesion Molecules, Cytokines and Chemokines}

Adhesion molecules such as N-cadherin, CD44 or the cytokine SDF-1 $\alpha$ and its ligand CXCR4 are essential for the control of vital HSPC functions, including mobilization and homing [42-51]. Burk et al. [52] used planar lipid membranes with precisely defined concentrations of specific ligands to determine the binding strength between human UCB-HSPCs and the BM niche. The relative significance of UCB-HSPC adhesion to the surrogate 
niche models via CXCR4/SDF-1a or N-cadherin was quantified by the fraction of adherent cells, the area of tight adhesion and the critical pressure for cell detachment. The authors demonstrated that the binding of UCB-HSPCs to the niche model is a cooperative process, and the adhesion mediated by the CXCR4/SDF-1 $\alpha$ axis is stronger than that mediated by hemophilic $\mathrm{N}$-cadherin binding. Statistical image analysis of stochastic morphological dynamics revealed that UCB-HSPCs dissipated energy by undergoing oscillatory deformation.

The CXCR4 antagonist plerixafor has been proven to be highly effective in clinical use for the mobilization of HSPCs [53-63], but the complexity of its interaction with HSPCs and the niche is still not fully understood. In a previous study by our group, the impact of plerixafor on the interaction between human BM-derived MSCs and human UCB-HSPCs was quantitatively assessed [64]. Measurement of SDF- $1 a$ levels in the supernatant of MSC cultures revealed that exposure to plerixafor led to a transient increase in SDF-1a levels but had no long-term effect. In a series of Transwell experiments, the addition of SDF-1 $\alpha$ significantly stimulated UCB-HSPC migration; this stimulation was almost completely abolished by the addition of plerixafor, confirming the direct impact of the CXCR4/SDF-1a interaction on the migration capacity of UCB-HSPCs. In a microstructural niche model, the chemotactic sensitivity of UCB-HSPCs was determined. UCB-HSPCs migrated actively along an SDF-1 $\alpha$ gradient within the microchannels and showed a surprisingly high sensitivity of UCB-HSPCs: a linear SDF- $1 \alpha$ concentration gradient of $20 \mathrm{pg} \mathrm{ml}^{-1} \mathrm{~mm}^{-1}$ was calculated [64]. This result indicated that UCB-HSPCs are able to follow a subtle concentration gradient toward the direction of the source of attractant. We further hypothesized that two synergistic effects of plerixafor occur simultaneously, consequently inducing the mobilization of HSPCs from the bone marrow into the peripheral blood: (1) HSPCs lose much of their ability to "sense" the natural SDF-1a gradient in the bone marrow, and (2) the SDF-1a gradient in the BM temporarily collapses due to the release of high amounts of SDF-1 $\alpha$ by MSCs after plerixafor treatment. For confirmation, we analyzed the direct effect of plerixafor on the migration of human UCB-HSPCs in a Transwell setup. We confirmed, in agreement with previous findings, that SDF-1 $\alpha$ is a potent trigger of HSPC migration, thereby acting as a chemokine [47, 48, 65-68]. The addition of plerixafor led to an almost complete inhibition of this effect, underlining the impact of the SDF-1 $\alpha /$ CXCR4 interaction on UCB-HSPC migration [64].

However, the involvement of additional factors or chemokines in this process in vivo is very likely. For instance, Steinl et al. [69] demonstrated the occurrence of highly elevated serum concentrations of matrix metalloproteinase- 8 in patients during granulocyte colony-stimulating factor-induced UCB-HSPC mobilization. SDF- $1 a$ can be proteolytically processed by treatment with metalloproteinase- 8 , and this degradation has a strong inhibitory effect on UCB-HSPC migration. This might also explain the high mobilization efficiency of the combination of granulocyte colony-stimulating factor and plerixafor in the clinical setting.

Taken together, these findings illustrate the high sensitivity of HSPCs to SDF-1 1 and emphasize the extremely fine-tuned nature of the interaction between HSPCs and their niche via the SDF-1a/CXCR4 axis, thereby making it a relevant subject to analyze in niche model systems.

\section{Shear Stress and Medium Flow}

Shear stress is an important parameter in regulating MSC growth and development. Zhao et al. [7] analyzed the biomechanical characteristics of MSCs within a 3D perfusion bioreactor system for two flow rates. A higher proliferation rate, higher CFU-F formation, and more fibronectin and HSP-47 secretion were observed at a lower flow rate. The higher flow rate upregulated the osteogenic differentiation potential, as measured by the expression of alkaline phosphatase activity and calcium deposition in the matrix, after 14 days of osteogenic induction.

Medium flow in bioreactor systems is generally controlled in either a parallel or transverse manner, creating different cellular and biomechanical microenvironments in the 3D constructs. Kim et al. [70] used a custom-designed modular perfusion bioreactor system that was operated under either parallel or transverse flow. The influence of the flow patterns on the characteristics of the MSC cellular microenvironment and subsequent construct development was investigated. The parallel flow configuration retained ECM proteins and mitogenic growth factors within the scaffold, effectively preserving MSC progenicity and proliferation potential, whereas transverse flow induced MSC osteogenic differentiation, with higher ALP activity and calcium deposition and upregulation of osteogenic bone markers.

There is strong evidence that macroscopic flow plays a regulatory role in the $3 \mathrm{D}$ cellular microenvironment of MSCs. However, configuring the medium flow to specifically direct MSC fate and 3D niche formation in perfusion bioreactor systems remains challenging.

\section{Cellular Composition of (Co)culture Systems}

In numerous studies, MSCs maintained the stemness of human HSPCs more efficiently through direct cell-cell contact in two-dimensional coculture systems than in suspension culture $[1,2,14,68,71]$. However, very recently, Wilkinson et al. [72] described the development of a defined, albumin-free culture system that supports the long-term ex vivo expansion of functional mouse hema- 
topoietic stem cells (HSCs). If these findings could be confirmed with human primary cells, it might be an important step toward enabling in vitro expansion of human HSPCs for transplantation. This represents a particularly relevant aim for clinicians who use UCB-HSCs for allogeneic transplantation because in this setting, the number of available HSPCs is naturally limited.

The next step for a more physiological in vitro environment was the development of $3 \mathrm{D}$ (co)culture systems. Bai et al. [73] have recently used a 3D culture system of human HSPCs in a degradable zwitterionic hydrogel and achieved substantial expansion of phenotypically primitive CD34+ cord blood and BM-derived HSPCs. This culture system led to a 73-fold increase in long-term HSC frequency, as demonstrated by limiting dilution assays, and the expanded HSPCs were capable of hematopoietic reconstitution in immunocompromised mice. Both the zwitterionic characteristics of the hydrogel and the $3 \mathrm{D}$ format were important for HSPC self-renewal. The authors concluded that the impact of 3D zwitterionic hydrogel culture on mitigating HSPC differentiation and promoting self-renewal might result from an inhibition of excessive reactive oxygen species production via suppression of $\mathrm{O}_{2}$-related metabolism [73].

In our hands, a 3D coculture system based on a custom-made chip could be established as an in vitro model system of the human HSC niche [74]. An array of up to 625 microcavities, with a size of $300 \mu \mathrm{m}$ in each orientation, was inserted into a microfluidic bioreactor. The microcavities of the microarray chip were inoculated with human BM MSCs together with umbilical cord blood HSPCs. The cells were mixed and inoculated into the microcavity chip, which was mounted into the microbioreactor, allowing active medium and gas supply. MSCs used microcavities as a scaffold to build a complex 3D mesh. UCB-HSPCs were distributed three-dimensionally inside this MSC network and formed $\beta$-catenin- and $\mathrm{N}$-cadherin-based intercellular junctions with the surrounding MSCs. A proportion of UCB-HSPCs maintained the expression of CD34 throughout a culture period of 14 days. Based on colony-forming unit assays, UCB-HSPC potency remained similar after bioreactor coculture. These results support the notion that the $3 \mathrm{D}$ microenvironment created within microcavity arrays and bioreactors seems to preserve the stem cell functions of HSCs more efficiently than conventional coculture systems.

However, it remains challenging to evaluate stemness, as most classical functional assays, such as colony-forming cell assays or even long-term culture-initiating cell assays, actually assess the activity of progenitor cells rather than stem cells. In addition, HSC heterogeneity must be considered, as well as the presence of lineage-biased HSCs and lineage-restricted progenitors within the HSC compartment [75]. The most important aspect that needs to be addressed in future studies is therefore to establish potency assays that indicate (preferably on a single-cell level) the impact of the specific microenvironment on HSPCs and their differentiation potential.

\section{Microbioreactor Systems as an Advanced Means to Mimic Nature}

Schmid et al. [10] developed a perfusion microbioreactor system that allowed the cultivation of 3D cell cultures in an oxygen-controlled environment in up to 4 independent operating bioreactors. A uniform flow distribution in the microbioreactor could be demonstrated using a computational fluid dynamics model. For oxygen measurements, microsensors were integrated into the bioreactors to measure the oxygen concentration in the geometric center of the 3D cell cultures. Furthermore, an automated cell seeding protocol was implemented. The human mesenchymal stem cell line SCP-1 was seeded on a bovine cancellous bone matrix and cultivated in the developed microbioreactor system at different oxygen levels. Oxygen control was capable of maintaining preset oxygen levels over a cultivation period of several days. In combination with the automated cell seeding procedure, this setup may allow more reproducible experiments, with the goal of generating tissue-engineered grafts in an oxygen-controlled environment.

Cimetta et al. [8] developed a microbioreactor providing time sequences of space-resolved gradients of multiple molecular factors in 3D cell culture settings, along with high-throughput operation and imaging compatibility. These microbioreactors provided multiple gradients of molecular factors in 3D cell culture settings, with complex sequences of time- and space-resolved gradients and the application of rapid dynamic changes in environmental signals. Due to the rapid establishment of steady-state conditions, the microbioreactors ensured the maintenance of precise and time-invariant compositions of the soluble microenvironment to which individual 3D stem cell aggregates were exposed. Embryoid bodies obtained from human embryonic and induced pluripotent stem cells were exposed to concentration gradients of Wnt3a, activin A, BMP4 and their inhibitors to analyze early-stage fate specification and mesodermal lineage commitment. The initiation of mesodermal induction was evaluated by measuring and correlating the gene expression profiles to the concentration gradients of mesoderm-inducing morphogens. The study demonstrated the modulation of pathway activation by the local microenvironment, resulting in nonlinear cell responses to linear concentration gradients. This example shows that microbioreactor systems combining spatial and temporal gradients of molecular and physical factors with human embryonic stem cell and induced pluripotent stem cell cultures may form a basis for predictable in vitro models of development and disease. 


\section{The Role of Oxygen Tension in the Bone Marrow \\ Niche}

In the bone marrow niche, a low partial oxygen pressure has been reported in the range of $1-7 \%$ [76-79]. However, there have been varying data published regarding the functional role of oxygen tension in the BM and its impact on HSPCs [80-87]. Hypoxic conditions apparently lead to increased self-renewal of human embryonic, hematopoietic, mesenchymal and neural stem/progenitor cells and improve the efficiency of genetic reprogramming to induce pluripotency [88]. When investigating enriched stem cell fractions, there is evidence that their metabolism depends on hypoxic conditions and glycolysis $[86,89]$.

Hypoxic conditions enhance osteogenic differentiation and allow stem cells to remain in an undifferentiated state and thus maintain their potential for multilineage differentiation [90-94]. Hypoxia-inducible factor-1 $\alpha$ is one of the most important regulators of cell metabolism. It is stabilized under low oxygen tension. With numerous downstream target genes and crosstalk with other signaling pathways, hypoxia-inducible factor- $1 \alpha$ regulates various metabolic pathways, such as the oxidative stress response, glycolysis and mitochondrial respiration [76, 95, 96]. Furthermore, hypoxia-inducible factor-1a is involved in the process of homing and mobilization of HSPCs [77, 91, 97].

Drolle et al. [98] reported that while no difference in hypoxia level could be detected between BM infiltrated by acute myeloid leukemia (AML) and healthy BM, physiological hypoxia of $1 \% \mathrm{O}_{2}$ led to cell cycle arrest of AML blasts in the $G_{0} / G_{1}$ phase, with upregulation of p27 and a consecutive decrease in cells in the $S$ phase. In addition, the susceptibility of AML blasts to cytarabine, an $S$ phase-dependent drug, was found to be significantly decreased, supporting the notion that low oxygen tension in the bone marrow niche might contribute to the chemoresistance of AML blasts. Cheloni et al. [99] reported that driver oncogenic proteins of several leukemias were suppressed following cell incubation at oxygen concentrations compatible with stem cell niche physiology. This suppression might represent a key positive regulator of leukemic stem cell survival and maintenance within the stem cell niche. It appeared that incubation at very low oxygen tension determined the suppression of driver oncogenic proteins and signals in a number of leukemia cell populations, leading to the hypothesis that this suppression is a more common phenomenon occurring in different types of cancers. In all of the tested types of leukemia in this study, oncogene suppression occurred only after incubation in very low oxygen, indicating that induction of the suppression mechanism was more likely related to the onset of severe energy restriction than simply "adaptation to hypoxia."
Thus, leukemic stem cells hosted in stem cell niches seemed suited to sustain the long-term maintenance of therapy-resistant minimal residual disease.

\section{Conclusions}

The human hematopoietic stem cell niche in the BM is three-dimensional, and any model system that aims to simulate its physiology should also be three-dimensional. In recent years, substantial progress has been made in constructing microbioreactor-based $3 \mathrm{D}$ systems to overcome the limitations of static cultivation techniques. Some of them take a number of the above-mentioned factors into account, which contribute to vital niche functions. We are just starting to understand the full potential of such systems. However, an open challenge is the development of precise read-out assays to determine the impact of niche properties on HSPC function. There is a need for new approaches that enable verification of the functional properties of the cells and might serve as potency assays in the context of novel cellular therapies.

\section{Acknowledgments}

We gratefully acknowledge the outstanding expertise and longstanding collaboration of Rainer Saffrich, our friend and colleague who passed away before completion of this paper.

\section{Conflict of Interest Statement}

The authors declare no conflicts of interest, except the following: P.W. - Member of Advisory Boards for Sanofi-Aventis.

\section{Funding Sources}

Research funding was provided by the German Red Cross Blood Service Baden-Württemberg - Hessen, Mannheim, Germany.

\section{Author Contributions}

P.W. substantially contributed to the conception of the work, the drafting and editing of the paper. A.D. and H.K. substantially edited and revised the paper critically for important intellectual content. 


\section{References}

1 Wagner W, Saffrich R, Wirkner U, Eckstein V, Blake J, Ansorge A, et al. Hematopoietic progenitor cells and cellular microenvironment: behavioral and molecular changes upon interaction. Stem Cells. 2005 Sep;23(8): 1180-91.

2 Jing D, Fonseca AV, Alakel N, Fierro FA, Muller K, Bornhauser M, et al. Hematopoietic stem cells in co-culture with mesenchymal stromal cells - modeling the niche compartments in vitro. Haematologica. $2010 \mathrm{Apr}$; 95(4):542-50.

3 Wein F, Pietsch L, Saffrich R, Wuchter P, Walenda T, Bork S, et al. N-cadherin is expressed on human hematopoietic progenitor cells and mediates interaction with human mesenchymal stromal cells. Stem Cell Res. 2010 Mar;4(2):129-39.

4 Schajnovitz A, Itkin T, D'Uva G, Kalinkovich A, Golan K, Ludin A, et al. CXCL12 secretion by bone marrow stromal cells is dependent on cell contact and mediated by connexin- 43 and connexin-45 gap junctions. Nat Immunol. 2011 May;12(5):391-8.

5 Ugarte F, Forsberg EC. Haematopoietic stem cell niches: new insights inspire new questions. EMBO J. 2013 Oct 2;32(19):2535-47.

6 Kristensen HB, Andersen TL, Patriarca A, Kallenbach K, MacDonald B, Sikjaer T, et al. Human hematopoietic microenvironments. PLoS One. 2021;16(4):e0250081.

7 Zhao F, Chella R, Ma T. Effects of shear stress on 3-D human mesenchymal stem cell construct development in a perfusion bioreactor system: experiments and hydrodynamic modeling. Biotechnol Bioeng. 2007 Feb;96(3): 584-95.

8 Cimetta E, Sirabella D, Yeager K, Davidson K, Simon J, Moon RT, et al. Microfluidic bioreactor for dynamic regulation of early mesodermal commitment in human pluripotent stem cells. Lab Chip. 2013 Feb;13(3):355-64.

9 Liu M, Liu N, Zang R, Li Y, Yang ST. Engineering stem cell niches in bioreactors. World J Stem Cells. 2013 Oct;5(4):124-35.

10 Schmid J, Schwarz S, Meier-Staude R, Sudhop S, Clausen-Schaumann H, Schieker M, et al. A perfusion bioreactor system for cell seeding and oxygen-controlled cultivation of threedimensional cell cultures. Tissue Eng Part C Methods. 2018 Oct;24(10):585-95.

11 McBeath R, Pirone DM, Nelson CM, Bhadriraju $\mathrm{K}$, Chen CS. Cell shape, cytoskeletal tension, and RhoA regulate stem cell lineage commitment. Dev Cell. 2004 Apr;6(4):48395.

12 Lutolf MP, Hubbell JA. Synthetic biomaterials as instructive extracellular microenvironments for morphogenesis in tissue engineering. Nat Biotechnol. 2005 Jan;23(1):47-55.

13 Discher DE, Mooney DJ, Zandstra PW. Growth factors, matrices, and forces combine and control stem cells. Science. 2009 Jun 26; 324(5935):1673-7.

14 Kadereit S, Deeds LS, Haynesworth SE, Koc ON, Kozik MM, Szekely E, et al. Expansion of LTC-ICs and maintenance of p21 and BCL-2 expression in cord blood CD34(+)/CD38(-) early progenitors cultured over human MSCs as a feeder layer. Stem Cells. 2002;20(6):573-82.
15 Calvi LM, Adams GB, Weibrecht KW, Weber JM, Olson DP, Knight MC, et al. Osteoblastic cells regulate the haematopoietic stem cell niche. Nature. 2003 Oct;425(6960):841-6.

16 Mendez-Ferrer S, Michurina TV, Ferraro F, Mazloom AR, Macarthur BD, Lira SA, et al. Mesenchymal and haematopoietic stem cells form a unique bone marrow niche. Nature. 2010 Aug;466(7308):829-34.

17 Bianco P. Bone and the hematopoietic niche: a tale of two stem cells. Blood. 2011 May; 117(20):5281-8.

18 Pinho S, Frenette PS. Haematopoietic stem cell activity and interactions with the niche. Nat Rev Mol Cell Biol. 2019 May;20(5):303-20.

19 Bieback K, Kern S, Klüter H, Eichler H. Critical parameters for the isolation of mesenchymal stem cells from umbilical cord blood. Stem Cells. 2004;22(4):625-34.

20 Wagner W, Wein F, Seckinger A, Frankhauser M, Wirkner U, Krause U, et al. Comparative characteristics of mesenchymal stem cells from human bone marrow, adipose tissue, and umbilical cord blood. Exp Hematol. 2005 Nov;33(11):1402-16.

21 Bianco P, Robey PG, Simmons PJ. Mesenchymal stem cells: revisiting history, concepts, and assays. Cell Stem Cell. 2008 Apr;2(4): 313-9.

22 Bieback K, Kern S, Kocaömer A, Ferlik K, Bugert P. Comparing mesenchymal stromal cells from different human tissues: bone marrow, adipose tissue and umbilical cord blood. Biomed Mater Eng. 2008;18(1 Suppl 1):S71-6.

23 Ho AD, Wagner W, Franke W. Heterogeneity of mesenchymal stromal cell preparations. Cytotherapy. 2008;10(4):320-30.

24 Bieback K, Wuchter P, Besser D, Franke W, Becker M, Ott M, et al. Mesenchymal stromal cells (MSCs): science and f(r)iction. J Mol Med (Berl). 2012 Jul;90(7):773-82.

25 Wagner W, Ho AD. Mesenchymal stem cell preparations - comparing apples and oranges. Stem Cell Rev. 2007 Dec;3(4):239-48

26 Bianco P, Cao X, Frenette PS, Mao JJ, Robey PG, Simmons PJ, et al. The meaning, the sense and the significance: translating the science of mesenchymal stem cells into medicine. Nat Med. 2013 Jan;19(1):35-42.

27 Wuchter P, Vetter M, Saffrich R, Diehlmann A, Bieback K, Ho AD, et al. Evaluation of GMP-compliant culture media for in vitro expansion of human bone marrow mesenchymal stromal cells. Exp Hematol. 2016 Jun; 44(6):508-18.

28 Wuchter P, Bieback K, Schrezenmeier H, Bornhauser M, Muller LP, Bonig $\mathrm{H}$, et al. Standardization of Good Manufacturing Practice-compliant production of bone marrow-derived human mesenchymal stromal cells for immunotherapeutic applications. Cytotherapy. 2015 Feb;17(2):128-39.

29 Schroeder T, Geyh S, Germing U, Haas R. Mesenchymal stromal cells in myeloid malignancies. Blood Res. 2016 Dec;51(4):225-32.

30 Raaijmakers MH, Mukherjee S, Guo S, Zhang S, Kobayashi T, Schoonmaker JA, et al. Bone progenitor dysfunction induces myelodysplasia and secondary leukaemia. Nature. 2010 Apr;464(7290):852-7.
31 Kode A, Manavalan JS, Mosialou I, Bhagat G, Rathinam CV, Luo N, et al. Leukaemogenesis induced by an activating beta-catenin mutation in osteoblasts. Nature. 2014 Feb; 506(7487):240-4.

32 Geyh S, Rodriguez-Paredes M, Jager P, Khandanpour C, Cadeddu RP, Gutekunst J, et al. Functional inhibition of mesenchymal stromal cells in acute myeloid leukemia. Leukemia. 2016 Mar;30(3):683-91.

33 Geyh S, Oz S, Cadeddu RP, Frobel J, Bruckner $B$, Kundgen A, et al. Insufficient stromal support in MDS results from molecular and functional deficits of mesenchymal stromal cells. Leukemia. 2013 Sep;27(9):1841-51

34 Medyouf H, Mossner M, Jann JC, Nolte F, Raffel S, Herrmann C, et al. Myelodysplastic cells in patients reprogram mesenchymal stromal cells to establish a transplantable stem cell niche disease unit. Cell Stem Cell. 2014 Jun 5;14(6):824-37.

35 Chen S, Zambetti NA, Bindels EM, Kenswill K, Mylona AM, Adisty NM, et al. Massive parallel RNA sequencing of highly purified mesenchymal elements in low-risk MDS reveals tissue-context-dependent activation of inflammatory programs. Leukemia. 2016 Sep; 30(9):1938-42.

36 Discher DE, Janmey P, Wang YL. Tissue cells feel and respond to the stiffness of their substrate. Science. 2005 Nov 18;310(5751):113943.

37 Caplan AI. Adult mesenchymal stem cells for tissue engineering versus regenerative medicine. J Cell Physiol. 2007 Nov;213(2):341-7.

38 Frank V, Kaufmann S, Wright R, Horn P, Yoshikawa HY, Wuchter P, et al. Frequent mechanical stress suppresses proliferation of mesenchymal stem cells from human bone marrow without loss of multipotency. Sci Rep. 2016 Apr 15;6:24264.

39 Fuchs E, Tumbar T, Guasch G. Socializing with the neighbors: stem cells and their niche. Cell. 2004 Mar 19;116(6):769-78.

40 Muth CA, Steinl C, Klein G, Lee-Thedieck C. Regulation of hematopoietic stem cell behavior by the nanostructured presentation of extracellular matrix components. PLoS One. 2013;8(2):e54778

41 Krater M, Jacobi A, Otto O, Tietze S, Muller $\mathrm{K}$, Poitz DM, et al. Bone marrow niche-mimetics modulate HSPC function via integrin signaling. Sci Rep. 2017 May 31;7(1):2549.

42 Puch S, Armeanu S, Kibler C, Johnson KR, Muller CA, Wheelock MJ, et al. N-cadherin is developmentally regulated and functionally involved in early hematopoietic cell differentiation. J Cell Sci. 2001 Apr;114(Pt 8):1567-77.

43 Lapidot T, Kollet O. The essential roles of the chemokine SDF-1 and its receptor CXCR4 in human stem cell homing and repopulation of transplanted immune-deficient NOD/SCID and NOD/SCID/B2m(null) mice. Leukemia. 2002 Oct;16(10):1992-2003.

44 Dar A, Goichberg P, Shinder V, Kalinkovich A, Kollet O, Netzer N, et al. Chemokine receptor CXCR4-dependent internalization and resecretion of functional chemokine SDF-1 by bone marrow endothelial and stromal cells. Nat Immunol. 2005 Oct;6(10):1038-46. 
45 Sugiyama T, Kohara H, Noda M, Nagasawa T. Maintenance of the hematopoietic stem cell pool by CXCL12-CXCR4 chemokine signaling in bone marrow stromal cell niches. Immunity. 2006 Dec;25(6):977-88.

46 Nie Y, Han YC, Zou YR. CXCR4 is required for the quiescence of primitive hematopoietic cells. J Exp Med. 2008 Apr 14;205(4):777-83.

47 Dar A, Schajnovitz A, Lapid K, Kalinkovich A, Itkin T, Ludin A, et al. Rapid mobilization of hematopoietic progenitors by AMD3100 and catecholamines is mediated by CXCR4dependent SDF-1 release from bone marrow stromal cells. Leukemia. 2011 Aug;25(8): 1286-96.

48 Zepeda-Moreno A, Saffrich R, Walenda T, Hoang VT, Wuchter P, Sanchez-Enriquez S, et al. Modeling SDF-1-induced mobilization in leukemia cell lines. Exp Hematol. 2012 Aug;40(8):666-74.

49 Hanke M, Hoffmann I, Christophis C, Schubert M, Hoang VT, Zepeda-Moreno A, et al. Differences between healthy hematopoietic progenitors and leukemia cells with respect to CD44 mediated rolling versus adherence behavior on hyaluronic acid coated surfaces. Biomaterials. 2014 Feb;35(5):1411-9.

50 Monzel C, Becker AS, Saffrich R, Wuchter P, Eckstein V, Ho AD, et al. Dynamic cellular phynotyping defines specific mobilization mechanisms of human hematopoietic stem and progenitor cells induced by SDF1alpha versus synthetic agents. Sci Rep. 2018 Jan 30; 8(1):1841.

51 Monzel C, Becker AS, Saffrich R, Wuchter P, Eckstein V, Ho AD, et al. Author correction: dynamic cellular phenotyping defines specific mobilization mechanisms of human hematopoietic stem and progenitor cells induced by SDFlalpha versus synthetic agents. Sci Rep. 2018 Apr 30;8(1):6996.

52 Burk AS, Monzel C, Yoshikawa HY, Wuchter P, Saffrich R, Eckstein V, et al. Quantifying adhesion mechanisms and dynamics of human hematopoietic stem and progenitor cells. Sci Rep. 2015 Mar 31;5:9370.

53 DiPersio JF, Micallef IN, Stiff PJ, Bolwell BJ, Maziarz RT, Jacobsen E, et al. Phase III prospective randomized double-blind placebocontrolled trial of plerixafor plus granulocyte colony-stimulating factor compared with placebo plus granulocyte colony-stimulating factor for autologous stem-cell mobilization and transplantation for patients with non-Hodgkin's lymphoma. J Clin Oncol. 2009 Oct; 27(28):4767-73.

54 DiPersio JF, Stadtmauer EA, Nademanee A Micallef IN, Stiff PJ, Kaufman JL, et al. Plerixafor and G-CSF versus placebo and G-CSF to mobilize hematopoietic stem cells for autologous stem cell transplantation in patients with multiple myeloma. Blood. 2009 Jun;113(23): 5720-6.

55 Fruehauf S, Ehninger G, Hubel K, Topaly J, Goldschmidt H, Ho AD, et al. Mobilization of peripheral blood stem cells for autologous transplant in non-Hodgkin's lymphoma and multiple myeloma patients by plerixafor and G-CSF and detection of tumor cell mobilization by PCR in multiple myeloma patients. Bone Marrow Transplant. 2010 Feb;45(2) 269-75.
56 Hubel K, Fresen MM, Salwender H, Basara N, Beier R, Theurich S, et al. Plerixafor with and without chemotherapy in poor mobilizers: results from the German compassionate use program. Bone Marrow Transplant. 2011 Aug;46(8):1045-52.

57 Taubert I, Saffrich R, Zepeda-Moreno A, Hellwig I, Eckstein V, Bruckner T, et al. Characterization of hematopoietic stem cell subsets from patients with multiple myeloma after mobilization with plerixafor. Cytotherapy. 2011 Apr;13(4):459-66.

58 Hubel K, Fresen MM, Apperley JF, Basak GW, Douglas KW, Gabriel IH, et al. European data on stem cell mobilization with plerixafor in non-Hodgkin's lymphoma, Hodgkin's lymphoma and multiple myeloma patients. A subgroup analysis of the European Consortium of stem cell mobilization. Bone Marrow Transplant. 2012 Aug;47(8):1046-50.

59 Nademanee AP, DiPersio JF, Maziarz RT, Stadtmauer EA, Micallef IN, Stiff PJ, et al. Plerixafor plus granulocyte colony-stimulating factor versus placebo plus granulocyte colony-stimulating factor for mobilization of CD34(+) hematopoietic stem cells in patients with multiple myeloma and low peripheral blood CD34 $(+)$ cell count: results of a subset analysis of a randomized trial. Biol Blood Marrow Transplant. 2012 Oct;18(10):156472.

60 Hundemer M, Engelhardt M, Bruckner T, Kraeker S, Schmitt A, Sauer S, et al. Rescue stem cell mobilization with plerixafor economizes leukapheresis in patients with multiple myeloma. J Clin Apher. 2014 Dec;29(6):299304

61 Cheng J, Schmitt M, Wuchter P, Buss EC, Witzens-Harig M, Neben K, et al. Plerixafor is effective given either preemptively or as a rescue strategy in poor stem cell mobilizing patients with multiple myeloma. Transfusion. 2015 Feb;55(2):275-83.

62 Sanchez-Ortega I, Querol S, Encuentra M, Ortega S, Serra A, Sanchez-Villegas JM, et al. Plerixafor in patients with lymphoma and multiple myeloma: effectiveness in cases with very low circulating CD34+ cell levels and preemptive intervention vs remobilization. Bone Marrow Transplant. 2015 Jan;50(1):349.

63 Baertsch MA, Kriegsmann K, Pavel P, Bruckner T, Hundemer M, Kriegsmann $M$, et al. Platelet count before peripheral blood stem cell mobilization is associated with the need for plerixafor but not with the collection result. Transfus Med Hemother. 2018 Jan;45(1): 24-31.

64 Wuchter P, Leinweber C, Saffrich R, Hanke M, Eckstein V, Ho AD, et al. Plerixafor induces the rapid and transient release of stromal cell-derived factor- 1 alpha from human mesenchymal stromal cells and influences the migration behavior of human hematopoietic progenitor cells. Cell Tissue Res. 2014 Feb; 355(2):315-26.

$65 \mathrm{Kim} \mathrm{CH}$, Broxmeyer HE. In vitro behavior of hematopoietic progenitor cells under the influence of chemoattractants: stromal cell-derived factor-1, steel factor, and the bone marrow environment. Blood. 1998 Jan 1;91(1): 100-10.
66 Mohle R, Bautz F, Rafii S, Moore MA, Brugger W, Kanz L. The chemokine receptor CXCR-4 is expressed on CD34+ hematopoietic progenitors and leukemic cells and mediates transendothelial migration induced by stromal cell-derived factor-1. Blood. 1998 Jun 15; 91(12):4523-30.

67 Faber A, Roderburg C, Wein F, Saffrich R, Seckinger A, Horsch K, et al. The many facets of SDF-1alpha, CXCR4 agonists and antagonists on hematopoietic progenitor cells. J Biomed Biotechnol. 2007;2007(3):26065.

68 Ludwig A, Saffrich R, Eckstein V, Bruckner T, Wagner W, Ho AD, et al. Functional potentials of human hematopoietic progenitor cells are maintained by mesenchymal stromal cells and not impaired by plerixafor. Cytotherapy. 2014 Jan;16(1):111-21.

69 Steinl C, Essl M, Schreiber TD, Geiger K, Prokop L, Stevanovic S, et al. Release of matrix metalloproteinase- 8 during physiological trafficking and induced mobilization of human hematopoietic stem cells. Stem Cells Dev. 2013 May 1;22(9):1307-18.

$70 \mathrm{Kim}$ J, Ma T. Perfusion regulation of hMSC microenvironment and osteogenic differentiation in $3 \mathrm{D}$ scaffold. Biotechnol Bioeng. 2012 Jan;109(1):252-61.

71 Walenda T, Bork S, Horn P, Wein F, Saffrich $\mathrm{R}$, Diehlmann A, et al. Co-culture with mesenchymal stromal cells increases proliferation and maintenance of haematopoietic progenitor cells. J Cell Mol Med. 2010 Jan;14(1-2): 337-50.

72 Wilkinson AC, Ishida R, Kikuchi M, Sudo K, Morita M, Crisostomo RV, et al. Long-term ex vivo haematopoietic-stem-cell expansion allows nonconditioned transplantation. $\mathrm{Na}$ ture. 2019 Jul;571(7763):117-21.

73 Bai T, Li J, Sinclair A, Imren S, Merriam F, Sun F, et al. Expansion of primitive human hematopoietic stem cells by culture in a zwitterionic hydrogel. Nat Med. 2019 Oct;25(10):156675.

74 Wuchter P, Saffrich R, Giselbrecht S, Nies C, Lorig H, Kolb S, et al. Microcavity arrays as an in vitro model system of the bone marrow niche for hematopoietic stem cells. Cell Tissue Res. 2016 Jun;364(3):573-84.

75 Haas S, Trumpp A, Milsom MD. Causes and consequences of hematopoietic stem cell heterogeneity. Cell Stem Cell. 2018 May 3;22(5): 627-38.

76 Dalloul A. Hypoxia and visualization of the stem cell niche. Methods Mol Biol. 2013;1035: 199-205.

77 Morikawa T, Takubo K. Hypoxia regulates the hematopoietic stem cell niche. Pflugers Arch. 2016 Jan;468(1):13-22.

78 Kwon SY, Chun SY, Ha YS, Kim DH, Kim J, Song PH, et al. Hypoxia enhances cell properties of human mesenchymal stem cells. Tissue Eng Regen Med. 2017 Oct;14(5):595-604.

79 Suessbier U, Nombela-Arrieta C. Assessing cellular hypoxic status in situ within the bone marrow microenvironment. Methods $\mathrm{Mol}$ Biol. 2019;2017:123-34.

80 Ivanovic Z, Dello Sbarba P, Trimoreau F, Faucher JL, Praloran V. Primitive human HPCs are better maintained and expanded in vitro at 1 percent oxygen than at 20 percent. Transfusion. 2000 Dec;40(12):1482-8. 
81 Grayson WL, Zhao F, Izadpanah R, Bunnell $\mathrm{B}, \mathrm{Ma}$ T. Effects of hypoxia on human mesenchymal stem cell expansion and plasticity in 3D constructs. J Cell Physiol. 2006 May; 207(2):331-9.

82 Parmar K, Mauch P, Vergilio JA, Sackstein R, Down JD. Distribution of hematopoietic stem cells in the bone marrow according to regional hypoxia. Proc Natl Acad Sci U S A. 2007 Mar 27;104(13):5431-6.

83 Simsek T, Kocabas F, Zheng J, Deberardinis RJ, Mahmoud AI, Olson EN, et al. The distinct metabolic profile of hematopoietic stem cells reflects their location in a hypoxic niche. Cell Stem Cell. 2010 Sep 3;7(3):380-90.

84 Baptista RP, Fluri DA, Zandstra PW. High density continuous production of murine pluripotent cells in an acoustic perfused bioreactor at different oxygen concentrations. Biotechnol Bioeng. 2013 Feb;110(2):648-55.

85 Rovida E, Marzi I, Cipolleschi MG, Dello Sbarba P. One more stem cell niche: how the sensitivity of chronic myeloid leukemia cells to imatinib mesylate is modulated within a "hypoxic" environment. Hypoxia (Auckl). 2014; 2:1-10.

86 Spencer JA, Ferraro F, Roussakis E, Klein A, Wu J, Runnels JM, et al. Direct measurement of local oxygen concentration in the bone marrow of live animals. Nature. 2014 Apr 10; 508(7495):269-73.

87 Hira VVV, Van Noorden CJF, Carraway HE, Maciejewski JP, Molenaar RJ. Novel therapeutic strategies to target leukemic cells that hijack compartmentalized continuous hematopoietic stem cell niches. Biochim Biophys Acta Rev Cancer. 2017 Aug;1868(1):183-98.

88 Hawkins KE, Sharp TV, McKay TR. The role of hypoxia in stem cell potency and differentiation. Regen Med. 2013 Nov;8(6):771-82.

89 Ito K, Suda T. Metabolic requirements for the maintenance of self-renewing stem cells. Nat Rev Mol Cell Biol. 2014 Apr;15(4):243-56.

90 Palomäki S, Pietilä M, Laitinen S, Pesälä J, Sormunen R, Lehenkari P, et al. HIF-1a is upregulated in human mesenchymal stem cells. Stem Cells. 2013 Sep;31(9):1902-9.

91 Guarnerio J, Coltella N, Ala U, Tonon G, Pandolfi PP, Bernardi R. Bone marrow endosteal mesenchymal progenitors depend on HIF factors for maintenance and regulation of hematopoiesis. Stem Cell Reports. 2014 Jun 3; 2(6):794-809.

92 Nombela-Arrieta C, Silberstein LE. The science behind the hypoxic niche of hematopoietic stem and progenitors. Hematol Am Soc Hematol Educ Program. 2014 Dec 5;2014(1): 542-7.

93 Kwon SY, Chun SY, Ha Y-S, Kim DH, Kim J, Song $\mathrm{PH}$, et al. Hypoxia enhances cell properties of human mesenchymal stem cells. Tissue Eng Regen Med. 2017;14(5):595-604.

94 Huang X, Trinh T, Aljoufi A, Broxmeyer HE. Hypoxia signaling pathway in stem cell regulation: good and evil. Curr Stem Cell Rep. 2018 Jun;4(2):149-57.
95 Zhang CC, Sadek HA. Hypoxia and metabolic properties of hematopoietic stem cells. Antioxid Redox Signal. 2014 Apr 20;20(12): 1891-901.

96 Testa U, Labbaye C, Castelli G, Pelosi E. Oxidative stress and hypoxia in normal and leukemic stem cells. Exp Hematol. 2016;44(7): 540-60.

97 Ceradini DJ, Kulkarni AR, Callaghan MJ, Tepper OM, Bastidas N, Kleinman ME, et al. Progenitor cell trafficking is regulated by hypoxic gradients through HIF-1 induction of SDF-1. Nat Med. 2004 Aug;10(8):858-64.

98 Drolle H, Wagner M, Vasold J, Kutt A, Deniffel C, Sotlar K, et al. Hypoxia regulates proliferation of acute myeloid leukemia and sensitivity against chemotherapy. Leuk Res. 2015 Jul;39(7):779-85.

99 Cheloni G, Poteti M, Bono S, Masala E, Mazure NM, Rovida E, et al. The leukemic stem cell niche: adaptation to "hypoxia" versus oncogene addiction. Stem Cells Int. 2017; 2017:4979474.

100 Gottwald E, Nies C, Wuchter P, Saffrich R, Truckenmüller R, Giselbrecht S. A microcavity array-based 3D model system of the hematopoietic stem cell niche. Methods Mol Biol. 2019;2017:85-95.

101 Ding L, Morrison SJ. Haematopoietic stem cells and early lymphoid progenitors occupy distinct bone marrow niches. Nature. 2013 Mar 14;495(7440):231-5.

102 Zhang B, Li M, McDonald T, Holyoake TL, Moon RT, Campana D, et al. Microenvironmental protection of CML stem and progenitor cells from tyrosine kinase inhibitors through $\mathrm{N}$-cadherin and Wnt-beta-catenin signaling. Blood. 2013 Mar 7;121(10):182438.

103 Choi JS, Mahadik BP, Harley BA. Engineering the hematopoietic stem cell niche: frontiers in biomaterial science. Biotechnol J. 2015 Oct;10(10):1529-45.

104 Kafi MA, Aktar MK, Phanny Y, Todo M. Adhesion, proliferation and differentiation of human mesenchymal stem cell on chitosan/collagen composite scaffold. J Mater Sci Mater Med. 2019 Nov;30(12):131.

105 Hafner J, Grijalva D, Ludwig-Husemann A, Bertels S, Bensinger L, Raic A, et al. Monitoring matrix remodeling in the cellular microenvironment using microrheology for complex cellular systems. Acta Biomater. 2020 Jul;111:254-66.

106 Ehninger A, Trumpp A. The bone marrow stem cell niche grows up: mesenchymal stem cells and macrophages move in. J Exp Med. 2011 Mar;208(3):421-8.

107 Walenda T, Bokermann G, Ventura Ferreira MS, Piroth DM, Hieronymus T, Neuss S, et al. Synergistic effects of growth factors and mesenchymal stromal cells for expansion of hematopoietic stem and progenitor cells. Exp Hematol. 2011 Jun;39(6):617-28.

108 Ramalingam P, Poulos MG, Butler JM. Regulation of the hematopoietic stem cell lifecycle by the endothelial niche. Curr Opin Hematol. 2017 Jul;24(4):289-99.
109 Sieburg HB, Cho RH, Dykstra B, Uchida N, Eaves CJ, Muller-Sieburg CE. The hematopoietic stem compartment consists of a limited number of discrete stem cell subsets. Blood. 2006 Mar;107(6):2311-6.

110 Anthony BA, Link DC. Regulation of hematopoietic stem cells by bone marrow stromal cells. Trends Immunol. 2014 Jan;35(1):32-7.

111 Zhou BO, Yue R, Murphy MM, Peyer JG, Morrison SJ. Leptin-receptor-expressing mesenchymal stromal cells represent the main source of bone formed by adult bone marrow. Cell Stem Cell. 2014 Aug;15(2): 154-68.

112 Busch K, Klapproth K, Barile M, Flossdorf M, Holland-Letz T, Schlenner SM, et al. Fundamental properties of unperturbed haematopoiesis from stem cells in vivo. $\mathrm{Na}$ ture. 2015 Feb 26;518(7540):542-6.

113 Kusumbe AP, Ramasamy SK, Itkin T, Mae MA, Langen UH, Betsholtz C, et al. Age-dependent modulation of vascular niches for haematopoietic stem cells. Nature. 2016 Apr;532(7599):380-4.

114 Asada N, Kunisaki Y, Pierce H, Wang Z, Fernandez NF, Birbrair A, et al. Differential cytokine contributions of perivascular haematopoietic stem cell niches. Nat Cell Biol. 2017 Mar;19(3):214-23.

115 Pinho S, Marchand T, Yang E, Wei Q, Nerlov C, Frenette PS. Lineage-biased hematopoietic stem cells are regulated by distinct niches. Dev Cell. 2018 Mar;44(5):634-641. e4.

116 Rehn M, Olsson A, Reckzeh K, Diffner E, Carmeliet P, Landberg G, et al. Hypoxic induction of vascular endothelial growth factor regulates murine hematopoietic stem cell function in the low-oxygenic niche. Blood. 2011 Aug 11;118(6):1534-43.

117 Nombela-Arrieta C, Pivarnik G, Winkel B, Canty KJ, Harley B, Mahoney JE, et al. Quantitative imaging of haematopoietic stem and progenitor cell localization and hypoxic status in the bone marrow microenvironment. Nat Cell Biol. 2013 May;15(5): 533-43.

118 Schaniel C, Sirabella D, Qiu J, Niu X, Lemischka IR, Moore KA. Wnt-inhibitory factor 1 dysregulation of the bone marrow niche exhausts hematopoietic stem cells. Blood. 2011 Sep;118(9):2420-9.

119 Lee-Thedieck C, Rauch N, Fiammengo R, Klein G, Spatz JP. Impact of substrate elasticity on human hematopoietic stem and progenitor cell adhesion and motility. J Cell Sci. 2012 Aug 15;125(Pt 16):3765-75.

120 Velten L, Haas SF, Raffel S, Blaszkiewicz S, Islam S, Hennig BP, et al. Human haematopoietic stem cell lineage commitment is a continuous process. Nat Cell Biol. 2017 Apr; 19(4):271-81. 